\title{
La creatininemia no es un estudio adecuado para la detección de insuficiencia renal en ancianos
}

Serum creatinine is an inadequate screening test for renal failure in elderly patients. Swedko $\mathrm{P}, \mathrm{Clark} \mathrm{H}$, Paramsothy $\mathrm{K}$, et al. Arch Intern Med.2003;163:356-360

\section{Objetivo}

Demostrar que la creatininemia no es un buen método para detectar insuficiencia renal (IR) en ancianos.

\section{Diseño}

Estudio retrospectivo sobre registros de pacientes mayores de 65 años atendidos en un centro ambulatorio.

\section{Lugar}

Hospital de Ottawa.Canadá.

\section{Pacientes}

Estudio realizado sobre 854 historias clínicas.

Descripción de los test y del test de referencia

Los autores recolectaron de los pacientes estudiados su creatininemia y calcularon su clearance de creatinina $(\mathrm{ClCr})$ según la fórmula de Crockcroft-Gault (ver Cuadro 1).Este último fue tomado como el test de referencia para definir IR $(\mathrm{CICr} \leq 50 \mathrm{~mL} / \mathrm{min})$.Luego, el valor de creatininemia fue comparado con el del $\mathrm{ClCr}$, utilizando como pruebas estadísticas el t test y chi cuadrado $(p \leq 0,05)$.
Cuadro 1:formula de Crockcroft-Gault para calculo del clearance de creatinina según edad, peso y creatininemia:

$$
\text { Clearance de creatinina }=\frac{(140-\text { edad en años }) \times \text { peso en } \mathrm{kg}}{72 \times \text { creatininemia en } \mathrm{mg} / \mathrm{dl}}
$$

Multiplicar por 0,85 si se trata de una mujer

\section{Resultados principales}

La prevalencia de IR fue $28,9 \%$. Un dosaje de creatinina mayor a $1,7 \mathrm{mg} / \mathrm{dL}$ mostró una sensibilidad del $12,6 \%$ para la detección de IR. El $87,4 \%$ de los pacientes con IR mostraron creatininemias menores o iguales a $1,7 \mathrm{mg} / \mathrm{dL}$.

\section{Conclusiones}

La creatininemia no es un estudio adecuado para detectar IR en ancianos.

\section{Comentario}

Si bien la conclusión de este estudio es correcta, vale aclarar que desde hace aproximadamente 30 años fue descrito que en los ancianos no se evidencia elevación de la creatinina plasmática pese a la reducción senil de su filtrado glomerular'. Esto se debe a que producen menos creatinina como consecuencia de su menor masa magra, de modo que se corre el riego de sobrestimar el filtrado glomerular de tenerse en cuenta sólo la creatininemia.

Un punto débil del trabajo que comentamos es que define como insuficiente renal al paciente con filtrado glomerular menor o igual a $50 \mathrm{~mL} / \mathrm{min}$. Teniendo en cuenta que la función glomerular declina normalmente a partir de los 30-35 años a razón de un mililitro por año, una persona normal suele tener $50 \mathrm{~mL} / \mathrm{min}$ a los $80 \mathrm{años}^{2}$. Por esta razón es incorrecto el valor de corte tomado para definir IR, ya que en una población envejecida (75 \pm 7 años) dicho filtrado podría ser el esperado para la edad.

Respecto de la evaluación del filtrado glomerular, recordemos que el test de referencia es el clearance de inulina, cuya ventaja sobre el de creatinina es que no depende de la masa muscular del paciente (se trata de una molécula exógena) y, además, sólo es filtrada a nivel renal, mientras que la creatinina normalmente es no solamente filtrada sino también secretada en alrededor de un $10 \%$.Incluso en pacientes con IR crónica, dicha secreción aumenta a medida que se reduce el filtrado glomerular.

Por otro lado, el clearance de creatinina medido ha sido criticado debido a su mala reproducibilidad ( $\mathrm{g}$ ran variación entre los valores de creatininuria de mediciones consecutivas) atribuyéndose este problema a inexactitudes en la recolección de orina ${ }^{3}$.

En cuanto a la fórmula de Crockcroft-Gault, que también a sido cuestionada, a la fecha sigue siendo un herramienta práctica y, desde ya, mucho mas confiable que el mero uso de la creatininemia.

Conclusiones del comentador: La creatininemia no es una prueba adecuada para el rastreo de insuficiencia renal en ancianos.

\section{Dr. Carlos Musso [ Servicio de Nefrología del Hospital Italiano de Buenos Aires ]}

\section{Referencias}

1.Cockcroft DW, Gault MH.Prediction of creatinine clearance from serum creatinine. Nephron.1976;16:31

2.Hernando Avendaño L, Lopez Novoa JM. Glomerular filtration and renal blood flor in the aged.In Macias Núñez JF, Cameron S (Eds).Renal function and disease in the elderly.London Butterworths. 1987: $42-43$

3.Goldber TH, Filkelstein MS.Difficulties in estimating glomerular filtration rate in the elderly.Arch Intern Med. 1987;147:1430. 